\title{
The Research on the enterprise production organization structure design based on process optimization
}

\author{
Guo Xiwei \\ School of Economic and Management \\ Shenyang Aerospace University \\ Shenyang, China \\ Quan Minghui \\ School of Economic and Management \\ Shenyang Aerospace University \\ Shenyang, China \\ e-mail: 1017075307@qq.com
}

\author{
Liu Xiaolian \\ School of Economic and Management \\ Shenyang Aerospace University \\ Shenyang, China \\ e-mail: 964755724@qq.com \\ Li Xue \\ School of Economic and Management \\ Shenyang Aerospace University \\ Shenyang, China \\ e-mail: 65520644@qq.com
}

\begin{abstract}
With the development of economy and increasingly fierce market competition, the realization of self-worth for customers themselves is pushed to a new level. With the progress of science and technology and information, the traditional organizational structure design won't satisfy the need of today's enterprise, thus the design of enterprise production organizational structure is developed based on the process optimization. Firstly, analyze the status quo and problems of the organizational structure. Secondly, introduce the development of the relevant organizational theories, propose process-centric organizational structure innovation, and then present the designing scheme of production organization based on the process optimization. Finally, analyze and research through its framework and design methods, and test our own ideas on the basis of the company's particular case.
\end{abstract}

Keywords- process optimization; organizational structure; production organization; optimization scheme.

\section{INTRODUCTION}

Process optimization, a theoretical system originated from the enterprise production organization reform and innovation, aims to help companies achieve management goals of high benefit, high quality, high flexibility and low cost. The advancement of conception and thoroughness of reform attract the attention of many enterprises.

Based on the status quo of Chinese enterprises and in view of the complex, rapidly changing and competitive environment, the new type of production organization structure is based on process optimization rather than function, whose basic construction centers on the core process for the design and cross-function team. The adoption of team eliminates the handover and transfer among departments, reduces the information delay or error, and improves the resilience and the reaction speed of the organization. In fact, the process itself is the center of the organization operation, which should be designed according to its own production capacity and the needs of customers; construct new organizations centered on process and design the organization structure through the optimization of process.

\section{DESIGN OF PRODUCTION ORGANIZATION STRUCTURE BASED ON PROCESS OPTIMIZATION}

\section{A Development of production organization structure}

The future organization will have the following features:

1) The organization will be operated in the environment requiring constant changes and adjustments;

2) The organization is required to adapt to the more and more diverse cultural values in the environment;

3) The future organization will adopt power-equal model rather than power inequality;

4) The method of coordinating the activities of each member in the organization is mainly to persuade and suggest, rather than stress on the basis of the power of the main characters;

The main trend of future organizational reform can be summarized as: flattening in structure, miniaturization in scale, flexibility, learning in pattern, etc.

Firstly, the flexibility of organization is required as the information which affects the organization under the action of the process and IT, has the characteristics of information sharing, widespread communications, differentiation and reorganization, and integration.

Secondly, organization flattening is to restructure the core business processes, the original organization framework and asset through information technology 
tools, and to streamline the surplus management; on the other hand, compress the management chain, shorten the management level, and achieve the redistribution of organizational power structure---move up the right to make decision and move down the right of management.

Thirdly, organizational modularity means to decompose and construct a number of fixed modules and make the organization function to realize random combination and rapid adjustment.

Fourthly, the learning organization refers to the organization of being good at acquisition, creation, and transfer of knowledge, and guided by the new knowledge, new ideas to modify their behaviors. Learning organization is also with a process of continuous learning, good at learning, constantly change and innovate, and a perfect, systematic feedback control loop and strong regeneration ability.

\section{B Structural framework of production organization}

based on process optimization

The organization structure based on the brand new ideas can better adapt to the above trend of the development of organization, which is to establish the team above the various core processes such as product development, material control, upgrading of process technology and the realization of customer value, etc. Organizational structure framework based on process optimization is divided into three parts, namely, the basic frame, the top management team and the information technology platform which are all built by dimension network of process and function.

The production organization structure based on process optimization can be divided into two level:

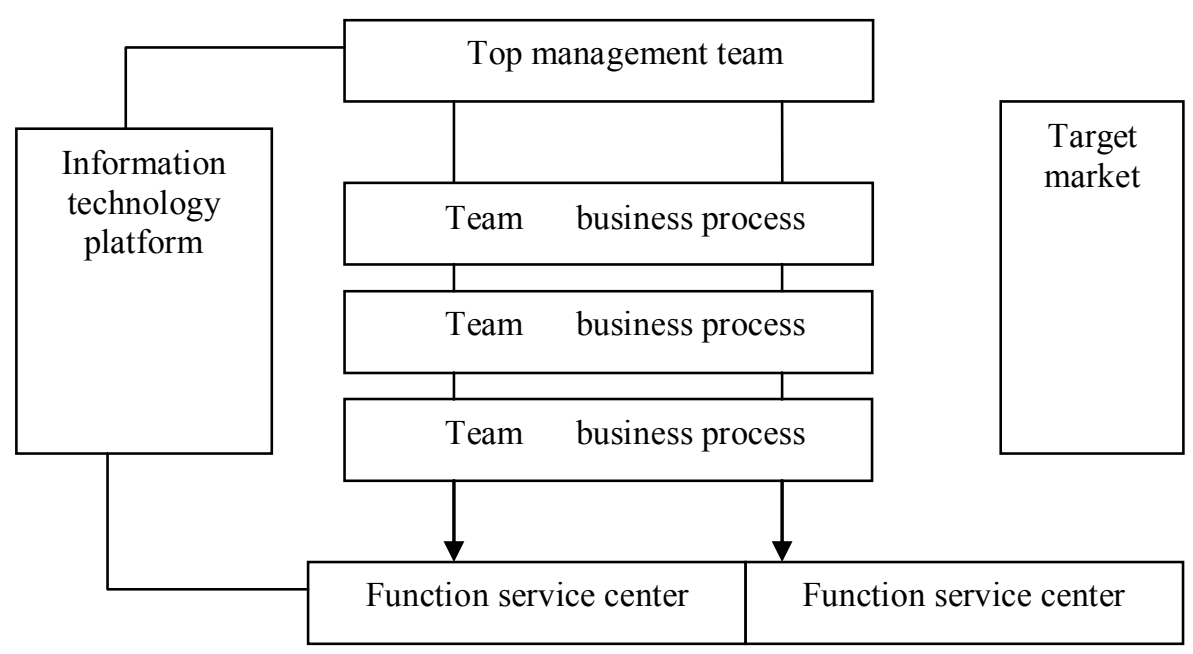

Graph 1 production organization framework based on process optimization

1) Centralized control level. The level of centralized control is at the top of the organizational structure. It centralizes the material control organization, human resources management, financial management, technology organization, information construction and management, and other important management functions with the role of grasping the key factors of organizational change. Centralized control has the power of controlling major events and decision-making right over major personnel and significant project investment. Internal affairs mainly include innovation of organizational structure, core business processes, enterprise mechanism as well as the construction of the company culture; the public affairs include stimulating the potential demand, expanding the market, and bringing about the sustainable development of enterprises.

2) Technology implementation level. The essence of technology implementation level is to divide specialists and knowledge-based talent into important technical department. Technical department is not only treated as the main structure of completing the task, but also can be used as the basis and standard of staff, technical and voluntary integration and optimization. The responsibilities of technology implementation level is to organize all the staffs with different competence who compose the task-oriented independent management teams, to form a virtual team in accordance with the project management methods.

Organization design based on process optimization focuses on the realization of customer's own value, centers on core processes for team-building, integrates the key factors of performance, and mobilize other organizational elements at the same time. Realize the 
value of the company by process, staff, and skills. It has process information for decision-making, can provide products and services timely, and maintain good relationship with the market and customers; it is a kind of production organization with new era characteristics.

\section{Design method of production organization structure based on process optimization}

\section{1) Definition of core business process}

\section{a) Trait analysis of core business process}

Core business processes is the enterprise in order to achieve business objectives, in accordance with customer demand, to the market, manufacture and provide products and services activities, namely direct activities create value for enterprises.

According to the path of the enterprise realizing its own value, it is a cycle from the recognition of need to the satisfaction, and reflects the value through exchange in the market. Therefore, the core business process of the enterprise can be viewed as recognizing the customer demand first and then meeting the demand, which is the horizontal integration process of business operations

\section{b) The core business process planning}

Marking out the core business process, the core value chain elements of enterprise, the needs of the enterprise's operation and management, customers' demand and matched management system requirements should all be noticed.

Grasping the core value chain elements of the enterprise refers to distinguishing the business activities that directly create value and those provide support services and assistance. Enterprise's business activity has the feature of lateral continuity, so the overall integrity should be noticed when designing related business process system, and the missing of important business link is not allowed.

\section{PROCESS TEAM BUILDING AND RELATED DUTY} SYSTEM

\section{A Ways of building process team}

To carry out the activities of process optimization within the enterprise, a special project team is required to carry out the process optimization activities in order to facilitate the project and obtain enough cooperation and care. The main task of the project team is to complete the design, analysis and improvement of enterprise internal process, and be responsible for the actual operation effect after optimal design. Under the guidance of project manager, the team reports the project progress to the company's top leaders regularly.

Before that, integrate the core business process work including those split previously, and build process team within the scope of integration.

The number of the process team is limited. The number must be reasonable; decide the size of the team according to the diversity and complexity of the task to be completed.

Process team should have the capacity of selfmanagement, self-decision and self-construction. Team members should have enough power to decide how the process can be achieved, including how to allocate resources and how to arrange time. It's independent internally.

One of the important factors of smooth team work is whether the resources are allocated in a good way. Production factors possessed by process are the resource of process and the basis of process capability.

\section{B Job responsibility system of organization based on process optimization}

The process is usually finished by the process team in the organization based on process optimization. Process team is usually composed of the process manager, functional personnel and process team. Director of the process is responsible for the coordination and surveillance of the whole core process, and for the executive level (General Manager). General Manager is responsible for the macro strategic decisions, and coordinates all processes. Relatively, functional department usually motivate and train the employees; the main executor of process is team member. Therefore, there are mainly five jobs in the organization based on process optimization, which are process manager, process director, senior leaders, functional managers, process team personnel (functional personnel). The specific responsibilities described as follows:

\section{1) Process manager}

Process manager is the planner, designer, conductor, galvanizer and coordinator. The specific duties are: record process optimization operation, maintain process design materials, customer demand and save completely process definition files, record the operation performance assessment and monitoring process.

\section{2) Process directors}

Directors of process are held by the executive level of enterprise, and report directly to the leader. Specific duties include: authorize each process manager and process team; coordinate and supervise all business processes; appraise performance of process team.

\section{3) Senior leaders}

Senior leaders of enterprise control and plan the overall strategy of enterprise process. Including: planning the overall goals of the whole enterprise and process, master scheduling and macro strategic, grasp the current enterprise's development vision, specify the enterprise internal resources integration, coordinate resources cooperation and distribution between process team; motivate the competition of the whole teams; cooperate with process manager and functional manager, and coordinate the relationship between at the same time.

\section{4) Functional manager}

Functional departments still plays an important role in organization based on process optimization, but the function of providing guarantee and support to the core business process should adjust according to different core business process. Functional managers are responsible for staff incentives, promotion and career development, and provide the high quality human resource service for employees 


\section{5) Process team staffs (functional personnel)}

Functional personnel are both bearers of professional skills and actual process team executives, so the role decides the duties. From the view of functional departments, it is a learning organization. As a team member, they exert their professional skills in the process team, execute enterprise process effectively, and continuously perfect the process. At work, they can effectively realize the requirement of professional skills to the process, and specify direction of study and research as the functional personnel.

\section{CONSTRUCT SUPPORT SYSTEM OF INFORMATION PLATFORM}

Organization development stage should be considered in the construction of Information platform as different life cycles face different problems as well as the information construction strategies and process optimization level of the organization. The key is how to connect the organization process of information platform construction in a better way; every organization should adopt corresponding strategies according to their own actual situation.

Three principles of process optimization design in constructing support system of information platform:

First, eliminate worthless links through the business process optimization

The goal of process optimization is to create value. Optimize according to the link in the process, and distinguish the place, role and value of each link. Optimize design for the useful and valuable key process, and eliminate the worthless links.

Second, focus on the core business process

Core process is the process with high value, and the key of process optimization design. Focus on the limited management resources in the company and maximize rewards.

Third, continuous improvement and optimization for process.

Process is continuous and requires constant innovation rather than a repeat of history. Continuous innovation and change capacity is the core values and core competitiveness in organization. After information construction and process optimization in the organization which is just the first step of change, the continuous improvement of organization process depends on the long-term ability of process improvement.

\section{PERFECT PERFORMANCE EVALUATION SYSTEM}

The two main sources of traditional enterprise performance indicators are KPIs based on strategy and KPIo based on function. Overwhelming emphasis on the effective operation of the department functions in traditional enterprises eventually leads to the higher and higher barrier between departments. The performance indicators of production enterprise based on process optimization also come from KPIs based on strategy and KPIp based on process. The process enterprise emphasizes the realization of the process and coordinates each department smoothly and efficiently through KPIp evaluation based on process.

\section{CONCLUSION}

Thesis research results are mainly showed in several aspects: First, introduce the development of organization theory and the development of all kinds of organization form, and analyze the current organization form as well as their advantages and disadvantages; Second, define the organization based on process optimization, put forward the structure framework, which is established on the enterprise core processes of cross-functional hill, and finally achieve the customerfocused goal of the enterprise; Third, propose the optimization design method of enterprise production organization based on process optimization, including the definition of core process, the process team building based on core process, the support system construction of information platform, and finally the resume of system performance evaluation; Fourth, analyze and solve problems combining with the specific circumstances of the company..

This thesis study the enterprise core business process on the basis of the related research at home and abroad, in combination with their research question and the related method theory, and research the problem on account of mismatching of current domestic enterprise production organization structure and market demand. This lead to the conclusions:

1) In the change-demand market environment, it's very difficult to seek the development of enterprise in the competitive environment if blindly insist on the original organization system. Correspondingly, based on internal core process design, assisted in the process of team building, enterprise can acquire unique production organization of itself.

2) Construction of information platform and its support system can play the role of connecting link and lubricant of each department to existing enterprise organization framework. What's more, the enterprise should redesign and optimize their core processes centering on the information flow, business flow, cash flow and logistics, and then redesign its organization framework hereby.

3) After redesigning enterprise production organization, the corresponding performance evaluation system should also be changed. We should match it with a suitable reference value system regardless of personnel, department or process.

\section{REFERENCES}

[1] Zhang Xuzhu. Research on the enterprise organization design based on the process optimization[D]. Shandong University, 201 .

[2] Yang Qin, Chen Ning. Research on the method of organization design based on the process[J]. Market Modernization, 2012, 36:53-54.

[3] Chen Ye. Research on the problem of performance management based on process optimization[D]. Nanjing University of Science and Technology, 2013.

[4] Zheng Hongyu. Research on the organization design based on process management from SD international company[D]. Shandong University, 2013. 
[5] He Zhen, Xu Xuemei. Quality management organization design of manufacturing enterprise based on process[J]. Journal of Tianjin University(Social science edition), 2011,05:403-407.

[6] $\mathrm{Xu}$ Xuemei. Quality management organization design of manufacturing enterprise based on process[D]. Tianjin University, 2012.

[7] Luo Wenqing. Organization optimization design based on process management[D]. Chongqing University, 2011

[8] $\mathrm{Xu} \mathrm{Lu}$. Systematic study on process-oriented organization design[D]. Shandong University, 2012.

[9] Liu Zhonghai. Research on the production process optimization of Nanpu Company[D]. Central South University, 2012
[10] He Wen. Production organization framework design of Shenhua Guohua Power Grid[D]. North China Electric Power University, 2012.

[11] Liu Shaomin. Technical research of process optimization based on process node[D]. Nanjing University of Aeronautics and Astronautics, 2012

[12] Yue Peng. Investigation on process-oriented organization construction[D]. Tongji University, 2013.

[13] $\mathrm{Hu}$ Dongju. Accounting organization design based on URP business process optimization $[\mathrm{J}]$. Green Finance and Accounting, 2011,06:30-31.

[14] Zeng Shaojun. Innovation research on China family firm organization[D].Capital University of Economics and Business, 2007. 